\title{
A influência do material e da técnica na arte contemporânea
}

\author{
Lenora Rosenfield
}

Universidade Federal do Rio Grande do Sul

\section{Resumo}

Esta pesquisa aborda algumas questões da influência matérica e técnica sobre a produção de uma artista. Em uma primeira etapa, relaciona a influência que Harold Bloom estuda, na literatura, da apropriação poética, o que o autor considera o ciclo vital do artista. E, em um segundo momento, faz um paralelo com a pintura, estudando o papel de Velázquez como um grande gerador de influência sobre outros artistas que o procederam. Por último, aplica essas questões na produção da arte contemporânea.

\section{Palavras-chave}

Influência, artista, material.

\section{The influence of materials and technique in contemporary art Abstract}

This research aims to analyze some problems of the influence related to materials and techniques in an artist's works. As a first step, it relates the influence that Harold Bloom studied in the literature, naming it misreading, considered by him the artist's vital cycle. In a second moment, it makes a parallel with painting, studying Velázquez's influence on other artists that came after him. At last, it studies the relationship of the aspects above with contemporary art production.

\section{Key-words}

Influence, artist, material.

\footnotetext{
* Lenora Lerrer Rosenfield é professora doutora, associada no Instituto de Artes da Universidade Federal do Rio Grande do Sul em Porto Alegre. Ela foi uma residente em Harvard Art Museum em Cambridge, MA, foi professora visitante pela Fulbright na New York University. Concluiu seu doutorado em Poéticas Visuais na Escola de Artes e Comunicação da USP.Realizou pos-doutorado na Università degli Study em Udine, e no Centro Internazionale di Alti Studi Latino Americani. Italia. Realizou várias exposições no Brasil e no exterior. Mora em Porto Alegre
} 


\section{Introdução}

Este trabalho é um recorte de uma pesquisa, ainda em andamento, sobre a influência e suas questões técnicas na pintura a óleo e os novos procedimentos na produção da arte contemporânea.

O início desta reflexão se deu quando fui a um espetáculo de guitarra. Fiquei impressionada com a competência do guitarrista. Perguntei a ele se seria possível tocar assim sem, antes, ter aprendido muita técnica. Ele me respondeu que, em sua opinião, não. Questionei, então, como ele tinha feito, considerando que, no período do fim do século $X X$, a técnica nas artes estava um pouco em desuso. Ele me respondeu que a técnica sempre fora importante, porém, naquele momento ela deveria ser, na opinião dele, invisível. Concluí: a técnica é um instrumento que não deve aparecer na obra de maneira óbvia.

Primeiramente, este artigo enfocará a questão histórica dos materiais e das técnicas pictóricas que influenciaram o desenvolvimento da pintura culminando em Velázquez como referência, traçando um paralelo com a obra de Shakespeare, tomando como base o livro The Anxiety of Influence, de Harold Bloom.

Em uma segunda etapa, abordará a relação dos materiais e dos procedimentos pictóricos nos processos de criação da obra de arte contemporânea, no caso particular de obras realizadas em afresco sintético.

\section{Aspectos da origem da pintura a óleo}

Para entendermos melhor a evolução da pintura, começaremos pelos primórdios da pintura a óleo e os primeiros registros do uso do óleo de linhaça, encontrados no Tratado Mappae Clavicula (do século XII, que parece significar 'chave do desenho'). Nesse tratado está mencionada a mistura do óleo de linhaça com algum tipo de resina para ser usado como 
verniz, mas não como tinta a óleo. Até então, não havia notícia de alguém ter misturado pigmentos sólidos com óleo. Somente nos tratados de Eraclius e Theophilus, escritos no século XIII, é que a mistura óleo/pigmento foi mencionada para fins artísticos.

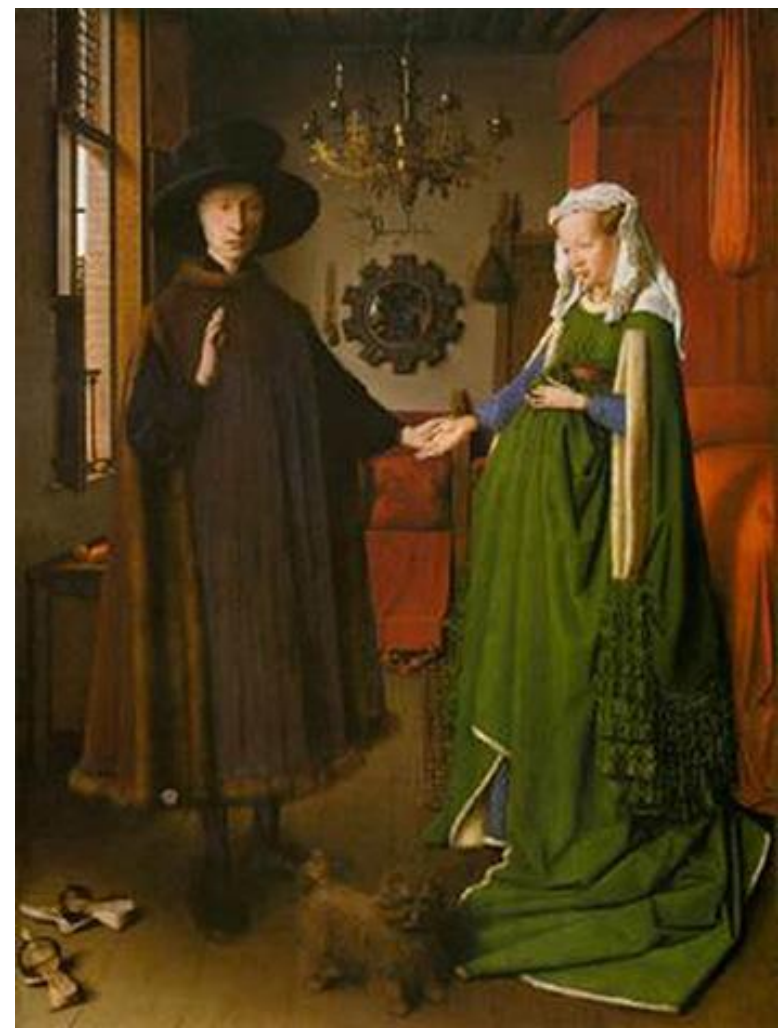

Fig. 1 - Jan Van Eyck (1390-1441) - "O Casal Arnolfini"- 1434 - óleo s/ madeira - 84,5 x $62,5 \mathrm{~cm}^{1}$

No séc. XIV, foi empregado o óleo de noz na pintura, sem sucesso. Ele é encontrado novamente em Van Eyck, no início do século XV. O verniz feito com óleo de noz e de linhaça, diferentes dos compostos de verniz à base de resina diluída em óleos essenciais, foi usado exclusivamente no século $\mathrm{XV}$. No início do século XVI, os italianos começaram a utilizar diversos sistemas relacionados aos primeiros progressos da pintura a óleo, com a utilização do verniz à base de óleos essenciais.

\footnotetext{
${ }^{1}$ Exemplo de pintura a óleo com veladuras. Alguns autores dizem que a técnica desta pintura é tempera e óleo.
} 
O uso de óleos essenciais foi um dos fatores que favoreceu a exploração das pinceladas e da aplicação da tinta. Provavelmente, a tinta óleo originou-se da adição de um solvente, como o óleo essencial, talvez de lavanda ou alho, na mistura de óleo de linhaça e pigmento, para favorecer a diluição, formando uma mistura apropriada para a pincelada. Esse procedimento foi sistematizado pelos irmãos Van Eyck (fig.1)e possibilitou a exploração de uma nova untuosidade à tinta, dando chances para 0 artista exprimir-se através da pincelada impulsiva, espessa e mais marcada (Laurie, 1967; figs. 2 e 3).

A adição do óleo essencial, além de ter melhorado a aplicação da pincelada (por quebrar a tensão superficial da tinta), tornou essa técnica semelhante à da têmpera, além de ajudar na secagem da pintura.

Conforme Ziloty, o desenvolvimento da pintura a óleo deveu-se também ao fato de que no final do século XV, foi usada pela primeira vez a destilação do álcool em quantidades comerciais, bem como a destilação de outros produtos, como a terebintina. Essas transformações, também segundo Ziloty, acabaram por refletir na utilização de outro suporte, pois, no século $\mathrm{XVI}$, iniciou-se o uso frequente da tela esticada no bastidor, diminuindo 0 uso da madeira como suporte para fins artísticos, já que, no século $\mathrm{XV}$, a tela era usada de maneira mais isolada e eventual.

O novo procedimento facilitou o transporte, pela comodidade do suporte, especialmente no caso de quadros de grandes dimensões, além da superfície da tela passar a oferecer novas possibilidades pictóricas. Essa superfície, por ser mais irregular, com vários tipos e espessura de trama, fascinou os artistas, que estavam habituados a trabalhar somente com a superfície lisa produzida pela base de preparação a gesso sobre a madeira, o que a fazia lisa. Na Idade Média, a tela era colada sobre a madeira do suporte; a textura da tela desaparecia pela aplicação de várias camadas de preparação. 




Fig. 2 - Velázquez (1599-1660) - "Philip IV, em marrom e prata" - data incerta, entre 1631 e 1635 - óleo s/ tela - 1.995 x $1.130 \mathrm{~m}$ 


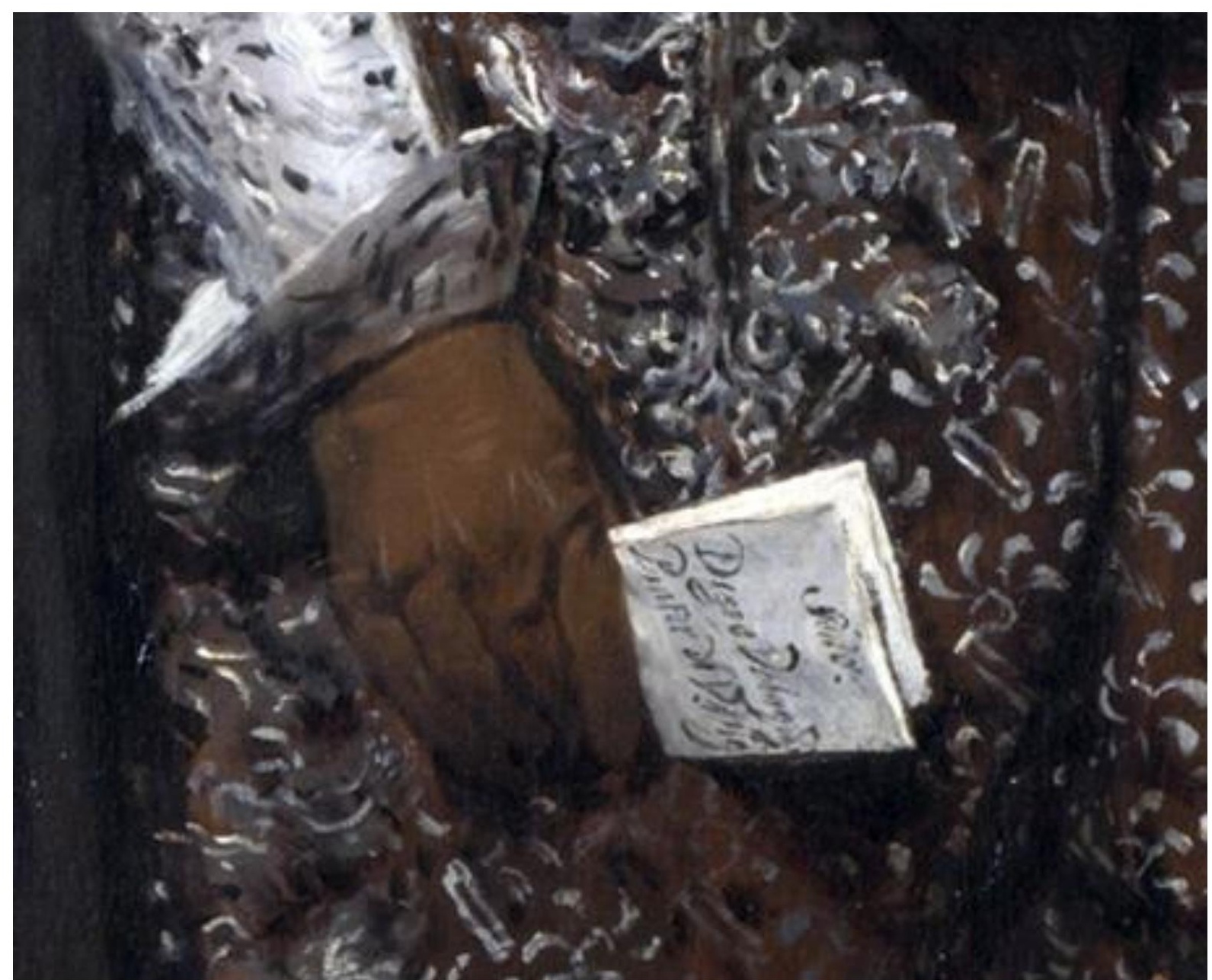

Fig. 3 - Detalhe figura 2

Vasari observou: "Para poder transportar uma pintura de um país ao outro, os homens descobriram a comodidade das telas pintadas, as quais pesam pouco e, ao mesmo tempo, são facilmente transportáveis." (Ziloty, 1947: 200).

O pintor flamengo Van Eyck (1390-1441), ativo desde 1422, não foi 0 primeiro a misturar óleo de linhaça com pigmento. Entretanto, ele e seu irmão foram os primeiros a sistematizar o método. É provável que daí venha o fato de Vasari ter atribuído aos irmãos Van Eyck a invenção da pintura a óleo. 
A partir desse fato, poderemos entender a repercussão da pintura a óleo e sua influência na arte ocidental através da obra de alguns artistas, considerados os grandes mestres deste processo.

\section{Aspectos da influência}

A influência, para Bloom, é simplesmente uma transferência de personalidade, um modo de abrirmos mão do que é mais precioso para 0 nosso eu, quando o seu exercício produz uma sensação e, talvez, uma realidade de perda. Todo discípulo toma alguma coisa do seu mestre, o que ocorre de maneira presencial direta ou indireta, como através de livros e exposições.

A palavra influência recebeu o sentido de "ter poder sobre o outro" já no latim escolástico de Tomás de Aquino, mas durante séculos não iria perder o sentido do radical "influxo" nem o sentido básico de emanação ou força vinda das estrelas sobre a humanidade. Como usada pela primeira vez, ser influenciado significava receber um fluido etéreo que descia das estrelas sobre nós, um fluído que afetava nosso caráter e destino, e que afetava todas as coisas sublunares. (Bloom, 1997: 76)

A influência poética, que Bloom chama de apropriação poética, é o estudo do ciclo vital do artista como artista, quando este é obrigado a examinar as suas relações com outros artistas, o que ele compara com o que Freud chamou de romance familiar, pois o artista discípulo mata, simbolicamente, 0 artista mestre.

Se retrocedermos no tempo e transportarmos esta ideia para a influência pictórica, focando mais na pincelada, encontraremos muitas coincidências e diferenças desde a origem da pintura.

Existem vários tipos de influências, sendo que uma delas é a subjetiva, com características mais imagísticas, espirituais ou psicológicas, diferentes das da matérica. A subjetiva proporciona a quebra do vínculo entre mestre e discípulo, diferentemente da física, ligada ao material e aos procedimentos de pintar. Nesse caso, um dos artistas mais citados na literatura como sendo o grande influenciador dos artistas do Ocidente, no que diz respeito 
à pincelada mais expressionista, entre outras coisas, foi Velázquez. Ele é considerado uma referência na maneira de pintar por ter sido mencionado por muitos artistas, de Goya a Manet, chegando até ao nosso lberê Camargo. Isto se deve ao seu uso diferenciado da tinta, no proveito da untuosidade desta, além de suas cores e pinceladas.

Seguindo esse raciocínio, depois de Velázquez, Cézanne (fig,4) formou um novo polo de influências, pois foi um artista que também inaugurou um novo olhar e procedimento na arte, pelo tratamento que deu à cor, à forma e à perspectiva, mas sempre mantendo uma pincelada expressiva e com movimento.

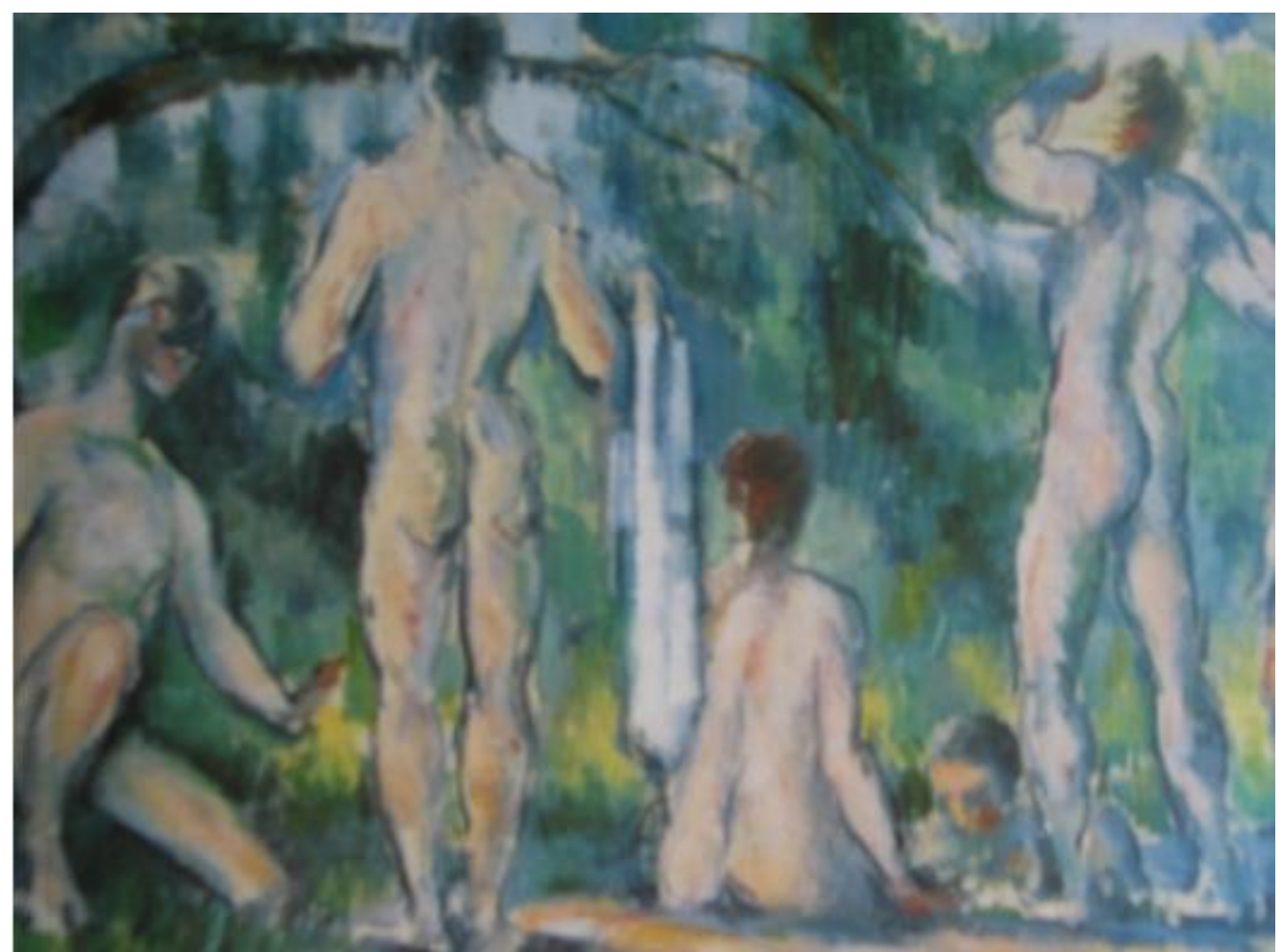

Fig. 4 - Cézanne (1839-1906) - "Banho" 1892-94 - Óleo s/ tela- 27 x 41 cm

Entre esses dois artistas existiram muitos outros, que alimentaram e conectaram de maneira aparentemente imperceptível essa trama de influências que ligou o passado ao presente, mas nem todos serão mencionados aqui. 
Em um retrocesso cronológico da história da arte, podemos mencionar que os artistas que mais influenciaram Velázquez foram El Greco e Caravaggio, pelo uso diferenciado da pincelada, da cor e da luz. Ele próprio não fazia segredo destas influências. A tendência de aplicar a tinta a óleo de uma maneira mais gestual atingiu o seu ápice nas obras do último período de Tiziano, depois de Rubens, de Rembrandt, de Velázquez, Goya, (fig. 5) continuando depois na pintura de Cézanne, no cubismo de Picasso, ("Les Demoiselles D'Avignon") e no expressionismo do século XX.

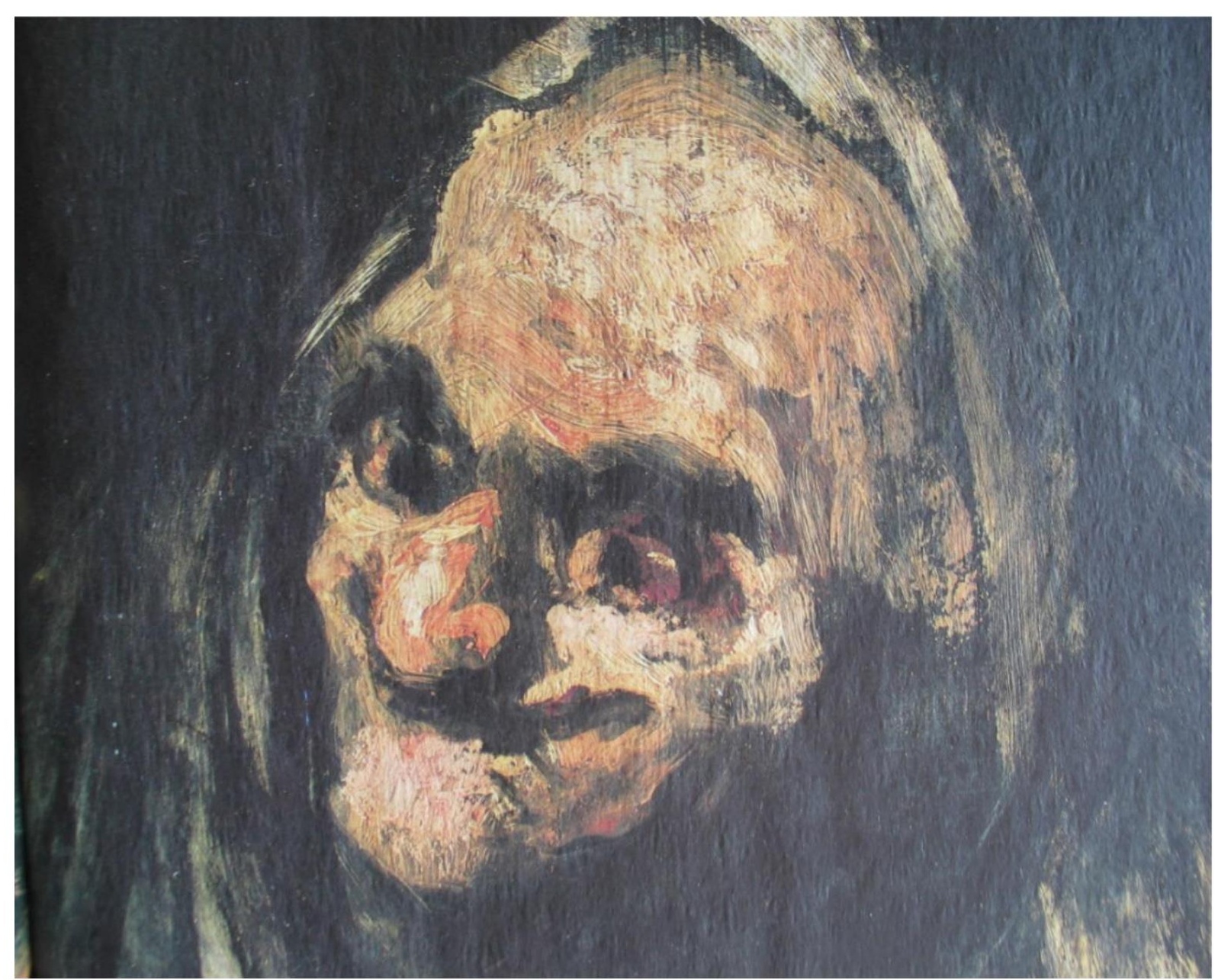

Fig. 5 - Goya (1746-1828) Detalhe de "O caldo da bruxa" agora óleo s/ tela - 55 x $85 \mathrm{~cm}$ - s/data ${ }^{2}$

${ }^{2}$ Agora óleo sobre tela, significa que esta pintura foi transportada da parede para tela, com a técnica de restauração chamada strappo. 
Este procedimento de pintar continuou se desenvolvendo, mas somente no final do século XIX os artistas, pela primeira vez, se afastaram do uso das veladuras, tradição da pintura flamenga, (fig. 1) passando a aplicar camadas mais grossas de tinta. No início do século XX, o uso das veladuras foi suprimido.

Dentro de um critério de artistas que se destacaram no seu tempo pelo uso diferenciado da pincelada, uso da cor e da luz, começamos por Caravaggio, como um artista que influenciou fortemente Velázquez, segundo o próprio. Caravaggio (1573-1610) nasceu perto de Milão, trabalhou principalmente em Roma, Nápoles, Malta e Sicília, e influenciou muitos holandeses. Sua característica era pintar com extremo realismo e usar a luz marcada contrastada com a sombra, obtendo dramaticidade e teatralidade. Pintava com pincéis macios e largos, que diluem a pincelada, não a deixando marcada. Tinha preferência pelos ocres, os vermelhões e o amarelo de Nápoles, que à base de chumbo.

Outro artista que influenciou Velázquez foi El Greco (1541-1614), nascido em Creta, vindo daí a influência dos ícones bizantinos (fig. 6 e 7 ). Em 1577, estabeleceu-se em Toledo. Suas figuras eram compridas e elegantes; as cores tendiam para o pálido. Foi influenciado pelos venezianos, mas, apesar de aplicar muitas veladuras translúcidas, estas eram pintadas sobre camadas opacas e espessas de cores mais claras, aplicadas de forma mais direta, com pincéis de cerdas mais duras. Este procedimento deixava a pincelada mais marcada e substituía as várias camadas de veladuras do método veneziano, aplicadas com pincéis macios, que produziam uma superfície uniforme. 


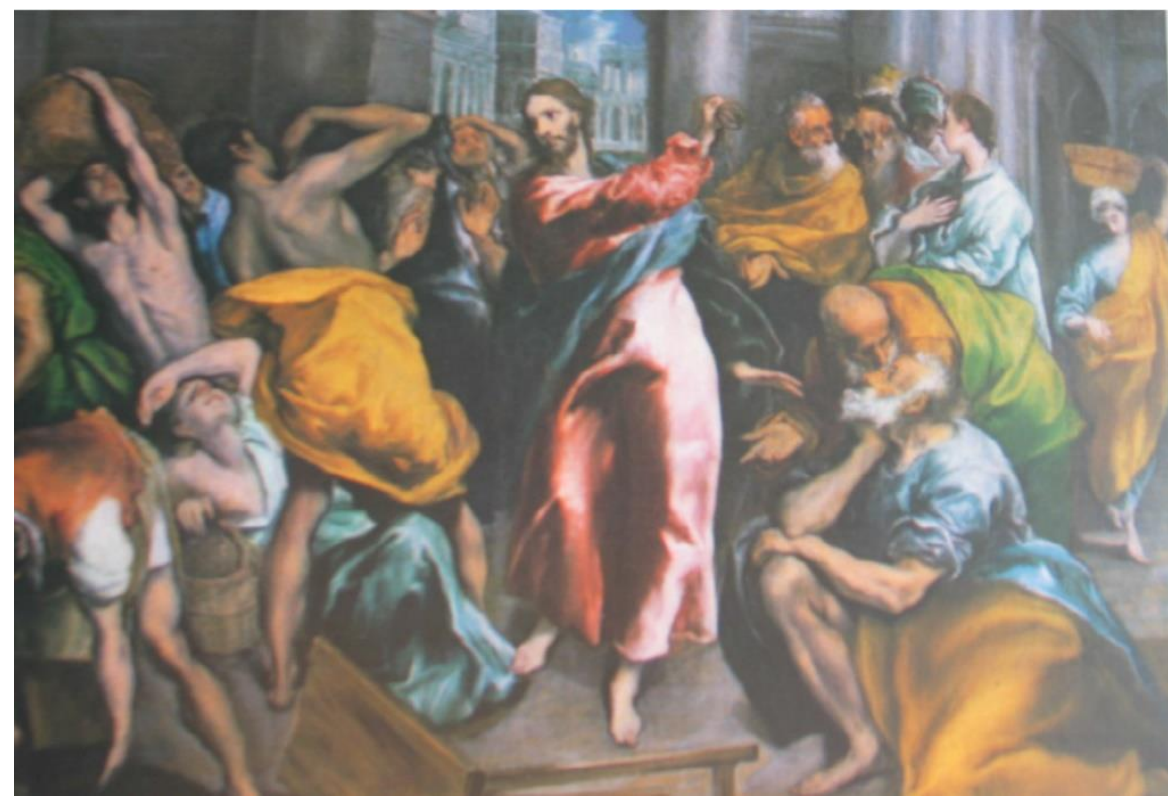

Fig. 6 - El Greco (1541-1614) - "Cristo expulsando os mercadores do templo" - 1600 - óleo s/tela, 106 × $130 \mathrm{~cm}$

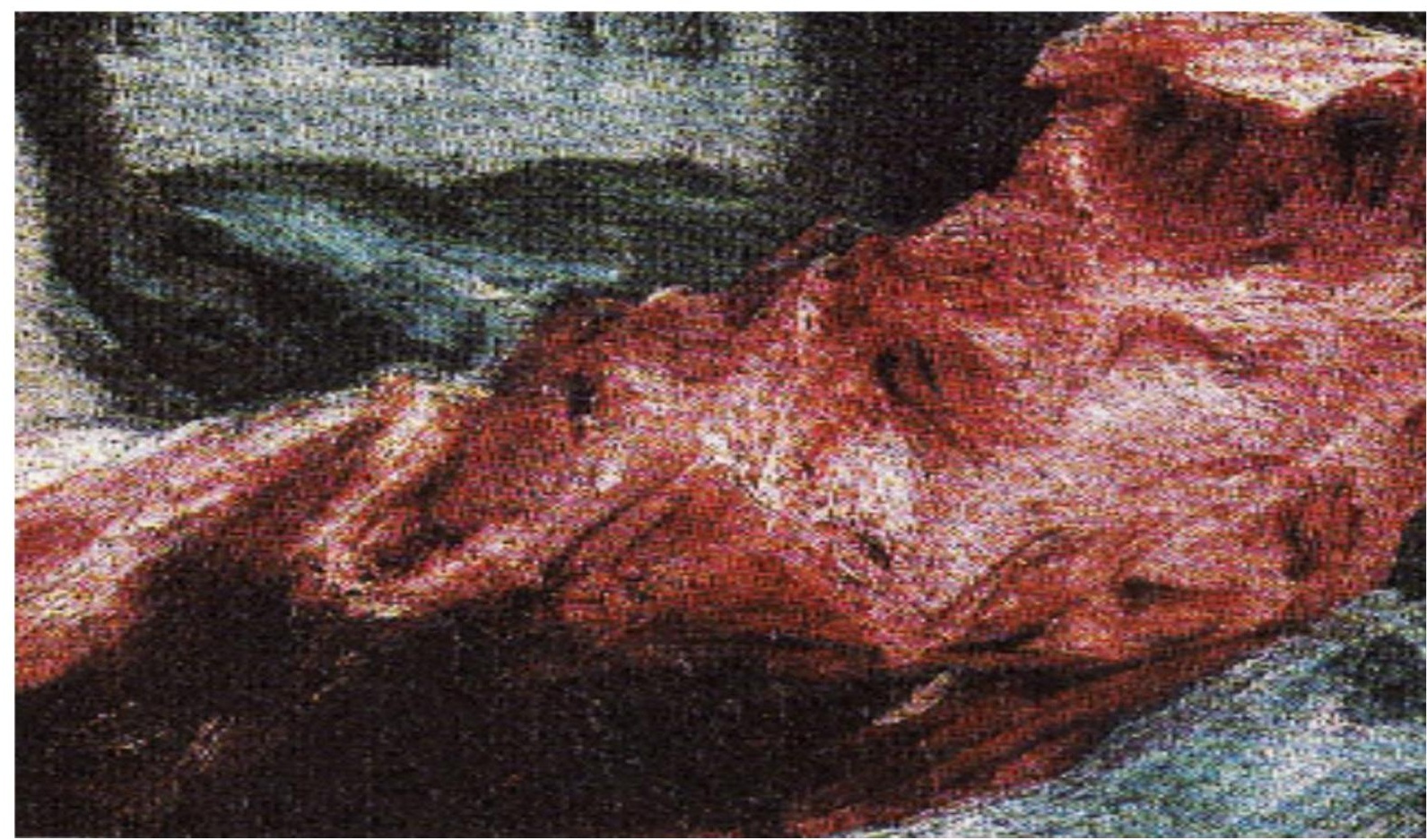

Fig. 7 - Detalhe figura 6

Velázquez (1599-1660) nasceu em Sevilha. Influenciou Goya e Manet. Como Caravaggio, tinha pinceladas suaves e fundidas, obtidas com pincéis 
mais macios. Também por influência deste, usava cores ocres e terra quentes, prestando especial atenção aos detalhes. Caravaggio também o influenciou em relação aos efeitos de luz sobre a pintura de um cristal. Velázquez desenvolveu uma técnica pictórica que mostrava os detalhes nítidos somente a uma certa distância (fig. 2). Um exemplo disso é a pintura "Philip IV, marrom e prata", em que Velázquez deixa de usar a pincelada fluida, passando a utilizar o impasto, e sugere, à distância, relevos do tecido da roupa.

Ao longo da carreira, a paleta de Velázquez ficou mais fria, e sua pincelada, mais livre, rápida e espontânea, com o uso de tinta mais espessa, o que acabou influenciando muito Goya, considerado (Licht, 1979) um dos primeiros expressionistas. Manet seria o próximo a fazer uso da pincelada com essas características.

Em suas primeiras obras, o francês Édouard Manet (1832-1883) empregou a técnica de pintar o úmido sobre o úmido e adotou o uso de pinceladas fortes, misturando as cores diretamente na tela. Suprimiu os tons médios, reforçando as áreas de luz e sombra, além de usar uma luz forte e direta. Teve forte influência da pintura espanhola, principalmente de Velázquez. 0 uso da luz, o aspecto de que a pintura havia sido realizada de uma só vez, a raspagem de toda a pintura, deixando uma camada inferior e recomeçando outra, de improviso, e a adoção de temas urbanos são procedimentos que transformaram Manet em uma ponte entre a pintura dos velhos mestres e a pintura moderna.

\section{A genealogia de uma influência na pintura}

Do ponto de vista técnico, a aplicação da tinta em formas de pontos e gestos pictóricos constituiu uma das grandes rupturas do século XIX, pois promoveu, segundo André Derain e Henri Matisse, a "orgia da cor pura". Essa ruptura teve, como uma de suas consequências, o fauvismo, que significou a expressão subjetiva da cor e sua harmonia. 
A explosão fauvista foi um ataque à arte oficial das academias e também uma reação contra o impressionismo, que continuou a ter exposições pósimpressionistas. Alguns autores consideram estas obras uma combinação dos principais elementos da arte de Cézanne, Van Gogh, Gauguin e Seurat. Os motivos continuavam sendo os mesmos: paisagens, retratos, naturezas mortas.

A cor não era usada com fins simbólicos e não era aplicada arbitrariamente, pois era empregada em função de exigências pictóricas, como a construção do espaço. A pincelada era livre, e as exigências da representação seguiam vigentes. As pinturas fauvistas conservaram a fidelidade tonal aproximada da natureza, e a cor era usada pela cor.

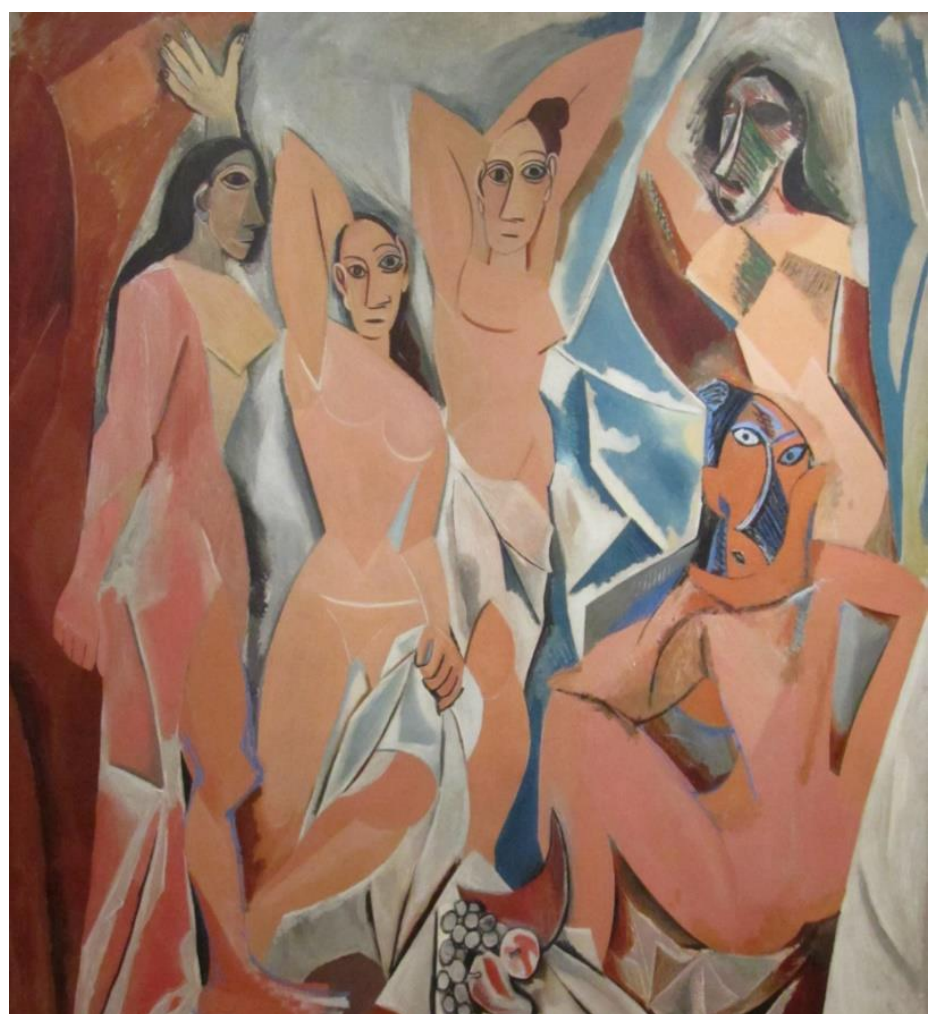

Fig. 8 - Picasso (1881-1973), "Les demoiselles D’Avignon" - óleo s/ tela -243.9 × $233.7 \mathrm{~cm}-1907$.

Assim como o fauvismo foi a exploração da cor e da pincelada, o cubismo (1907-1914) representou a da forma, rechaçando a perspectiva tradicional e criando um novo espaço pictórico. A característica principal do cubismo 
era combinar pontos de vista e perfis diferentes na mesma figura. Em relação a este movimento na arte, cabe mencionar que, depois que Picasso viu o trabalho de Cézanne em 1906, começou a experimentar a espacialidade do plano, explorando áreas de sombra e luz, ao invés das formas de volume arredondadas, para criar um sentido de espaço e forma. Esta influência desencadeou uma nova percepção na pintura, como podemos observar na obra de Picasso "Les demoiselles D'Avignon", obra figurativa que representa cinco nus no interior de um bordel. (fig. 8)

Nesta obra de 1907, originária da escultura ibérica e das máscaras africanas, nota-se a influência de Cézanne na simplificação das formas nos elementos mais primitivos, bem como da pintura "As Três Banhistas" do francês: três figuras concentradas em uma composição. Matisse também pode ter influenciado Picasso no movimento das figuras, na pintura "Dança". No lado direito de "Les demoiselles", observa-se o uso de linhas amarradas e cortes geométricos. A figura tem movimento e representação de vários ângulos que podem ser vistos simultaneamente. A superfície ainda contém certa modulação obtida pela cor, e há traços paralelos, como um hachurado, que produzem sombra ou relevo. Tal procedimento também é observado na cesta de frutas, que se sobressai na composição da pintura, devido a sua nitidez e colocação angular.

O rompimento com as perspectivas espacial e temporal clássicas torna-se mais claro. Estabelece-se a distorção decorrente da diferença entre 0 contorno contínuo e o descontínuo. Picasso duelou consigo mesmo para produzir o volume sem relacioná-lo com o plano de fundo e com a luz. Nesse sentido, queria romper com a influência de Velázquez, que produzia planos com o espelho, e de Caravaggio, que produzia o volume com a luz.

Com isso, Picasso estabeleceu um espaço pictórico pouco profundo, com cores pouco explosivas, usando a pincelada como um recurso pictórico, ainda sob influência de Velázquez, relacionada ao expressionismo, que surgiu posteriormente. 
As outras características do cubismo e suas influências não serão abordadas aqui, pois parecem ligadas a outros aspectos da pintura, que não são relacionados ao expressionismo, e sim ao uso da cor e à exploração do volume, não dando maior relevância à expressão da pincelada em si.

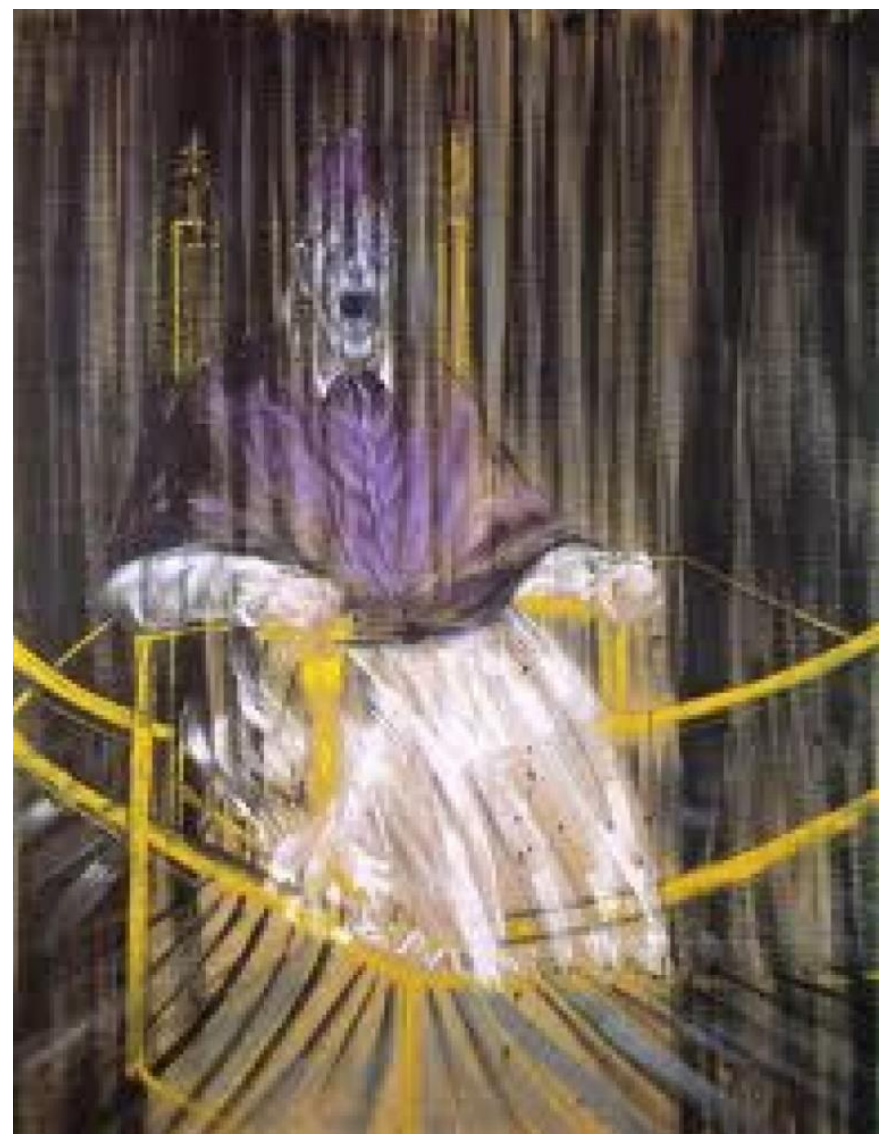

Fig. 9 - Francis Bacon (1909-1992) - Estudo depois de Velázquez de "Retrato do Papa Inocêncio X" - 153 x 118 cm - 1953

Continuando na linha de construção da pincelada expressionista que teve Velázquez como grande percursor, chegamos a Bacon, que também foi influenciado por esta cadeia formada por artistas como Velázquez, Rembrandt, Goya e Van Gogh.

Além de possuir uma pincelada livre, Bacon (fig. 9) iniciava sua pintura através de uma pincelada controlada, mais acidental sobre a tela, 
originando movimentos violentos, para formar a figura em ambientes domésticos ou paisagens. Neste aspecto, podemos lembrar a pintura de Velázquez. O espanhol limpava o pincel na própria tela, deixando a pincelada marcada como um pretexto para continuar a própria pintura. Observa-se, em Bacon, a pincelada intensa e carregada de tinta, como que arrancando uma verdade humana de dentro da tela e das cores da tinta, longe do naturalismo e da descrição das formas e aparências.

No expressionismo, o principal é a exteriorização das emoções do artista, manifestas através de distorções ou exageros da forma, da cor e da pincelada. O termo foi usado em 1911 para descrever certas obras, em uma exposição fauvista e cubista realizada em Berlim.

\section{Conclusão}

No processo do desenvolvimento da pincelada na pintura, uma das características do expressionismo, observamos que, ao longo da história, esta foi se modificando, no que tange à sua aplicação. Na tradição da pintura bizantina e flamenga, a pincelada era aplicada em veladuras transparentes sobre as camadas chapadas de variados tipos de têmpera. Com o surgimento do uso do óleo misturado com pigmento adicionado a um óleo essencial a partir do século XV, passou a explorar a untuosidade da tinta, desenvolvendo, a partir daí, uma pincelada cada vez mais gestual, marcada por pelos dos pincéis, dando maior expressividade para a pintura, como se pode notar no impressionismo. Esta característica culminou no expressionismo, em que a pincelada era aplicada de forma espessa, densa e marcada, em forma de veladuras opacas, chamada "esbatimento" (termo criado pela autora).

$\mathrm{Na}$ pintura da arte contemporânea, a pincelada reassumiu as características iniciais da sua tradição. Após o expressionismo, voltou a ser aplicada em camadas mais diluídas, mas não necessariamente transparentes. Esta característica foi muito evidenciada pela arte contemporânea, que diminuiu a importância da emoção do artista. 


\section{Aplicação desta pesquisa na arte do afresco contemporâneo}

Um exemplo de influência na arte contemporânea é o afresco sintético. Originalmente, é uma técnica de pintura tradicionalmente executada sobre paredes, que consiste em pintar sobre reboco fresco ou molhado à base de hidrato de cálcio, com pigmentos moídos em água. A tinta penetra na superfície do reboco ainda úmido, incorporando-se a este durante a secagem. 0 processo ocorre devido a uma reação química, na qual 0 hidrato de cálcio $\mathrm{Ca}(\mathrm{OH}) 2$ da superfície entra em lenta combinação com o dióxido de carbono, sempre presente no ar, para formar o carbonato de cálcio: $\mathrm{Ca}(\mathrm{OH}) 2+\mathrm{CO} 2 \rightarrow \mathrm{CaCO} 3+\mathrm{H} 2 \mathrm{O}$.

Os exames feitos nas pinturas de Lascaux deram origem a novas hipóteses sobre o uso de meios e pincéis. É provável que, através dos séculos, tenham se formado crostas de carbonato de cálcio nas paredes pintadas das cavernas, que migraram da rocha e se cristalizaram na superfície. Aparentemente, os pigmentos eram aplicados a seco, sem aglutinante sobre o suporte úmido, com auxílio de tubo vaporizador ou pincéis rudimentares. A migração do carbonato de cálcio promoveu a fixação do pigmento no suporte úmido, como ocorre em um afresco.

Cabe salientar que tal fenômeno ocorreu devido a uma série de fatores favoráveis, preexistentes na caverna, tais como condições climáticas e geológicas. Quantidades determinadas de carbonato de cálcio exsudado da rocha, combinadas com quantidades específicas de umidade produziram as quantidades exatas de carbonato de cálcio. É importante registrar que o excesso de carbonato de cálcio poderia esconder a pintura, e sua escassez impediria a fixação do pigmento.

Tais informações tornaram possível o desenvolvimento, na arte contemporânea, de novos tipos de procedimentos de afrescos, como os sintéticos, cuja base de preparação é uma mistura de argamassa, de fácil confecção e manuseio, guardando as mesmas características do afresco 
tradicional, aplicada sobre um suporte de não-tecido, que permite fazer afrescos flexíveis e portáteis. Esses afrescos podem apresentar pinceladas mais marcadas ou veladuras mais diluídas que não evidenciam o uso do pincel. Neste caso, devido ao suporte, que tem uma textura própria, a superfície pode ser explorada de maneira lisa ou texturizada.

Este tipo de trabalho é uma pesquisa sobre o procedimento do afresco, sua história, materiais e a expressão artística contemporânea, que forma uma trama metafórica de elementos movidos por história da arte, materiais, intenção estética, integrados a um suporte físico de um não-tecido. Esta combinação multidisciplinar forma uma grade de influências e de apropriações amarradas pelo poder inconsciente que artistas do passado exercem sobre os do presente.

\section{Referências}

BLOOM, Harold. The anxiety of influence: a theory of poetry. 2. ed. New York: Oxford University Press, 1997.

BLATT, Ethel S.; BLATT, Sidney. Continuity and Change in Art: The Development of Modes of Representation. Hillsdale: Laurence Erlbaum Associates, 1984.

CHILVERS, lan. Dicionário Oxford de Arte. Tradução de Marcelo Brandão Cipolla. São Paulo: Martins Fontes, 1996.

CHIPP, H. B. Teorias da arte moderna. São Paulo: Martins Fontes, 1993.

EASTLAKE, Sir Charles Lock. Methods and materials of painting of the great schools and masters. 2 vol. New York: Dover Publications, 1960.

JANUSZCZAK, Waldemar. Técnicas de los grandes pintores. Espanha: H.Blume Ediciones, 1981.

LAURIE, A.P. The painter's methods and materials. New York: Dover Publications, 1967.

LICHT, Fred. Goya: the origins of the modern temper in art. New York: Harper \& Row Publishers, 1983.

MORA, P.; MORA, L.; PHILIPPOT, P. Conservation of wall paintings. London: Butterworths, 1984.

MORASSI, Antonio. G.B. Tiepolo. Milano: Phaidon-Sansoni, 1943.

ROSENFIELD, L. L. A pintura a óleo e a questão Van Eyck. Porto Alegre: Porto Arte (UFRGS), v. 2, p. 39-44, 1990. 
ZILOTY, Alexandre. La découverte de Jean Van Eyck et l'évolution du procédé de la peinture à l'huile du Moyen Âge à nos jours. Paris: Librairie Floury, 1947.

Artigo recebido em janeiro de 2016. Aprovado em março de 2016 